\title{
2
}

\section{The state of play in cross-border electricity trade and the challenges towards a global electricity market environment SPYROS CHATZIVASILEIADIS AND DAMIEN ERNST}

\begin{abstract}
A. Introduction
Increased environmental awareness has led to concrete actions in the energy sector in recent years. Examples include the European Commission's target of 20 per cent participation of renewable energy sources (RES) in the European Union (EU) energy mix by 2020 (European Commission, 2008) and California's decision to increase renewable energy in the state's electricity mix to 33 per cent of retail sales, again by 2020 (State of California, 2011). At the same time, several studies have investigated the possibilities of a higher share of renewables in the energy supply system of the future. For instance, the German Energy Agency (dena) assumes 39 per cent RES participation by 2020 (Deutsche Energie-Agentur (dena), 2010), while a detailed study from the National Renewable Energy Laboratory (NREL) suggests that meeting the US electricity demand in 2050 with 80 per cent RES supply is feasible (Hand et al., 2012).
\end{abstract}

In 2011, Czisch discussed the possibility of having a 100 per cent renewable energy supply system in Europe with interconnections in North Africa and West Asia. Furthermore, Jacobson and Delucchi (2011) investigated 'the feasibility of providing worldwide energy for all purposes (electric power, transportation, heating/cooling, etc.) from wind, water, and sunlight'. The authors made a detailed analysis and proposed a plan for implementation. They found that the barriers to the realisation of this plan are not technological or economic, but rather social and political.

All these studies suggest that the development of the electricity network will play a crucial role in the efficient integration of increasing shares of renewables for two main reasons. First, interconnecting RES increases the reliability of supply. Second, long transmission lines can help harvest renewable energy from remote locations with abundant potential and very low production costs. Concrete actions have been taken to exploit the benefits of such interconnections, which will lead to the creation of regional supergrids. EU guidelines already encourage transmission projects such as the Baltic Ring (Boute and 
Willems, 2012). Projects such as Medgrid, ${ }^{1}$ and OffshoreGrid ${ }^{2}$ have been launched, with the aim of interconnecting Mediterranean states with Europe and transferring renewable energy to the major load centres. At the same time, initiatives such as Gobitec ${ }^{3}$ in Asia and Atlantic Wind Connection ${ }^{4}$ in the USA aim to interconnect the Asian power grids or transmit offshore wind energy to the US east coast.

Expanding the regional transmission grids to supergrids, building new lines and reinforcing existing interconnections is necessary to minimise the need for balancing energy from conventional generators as well as to decrease the need for storage.

In Section B of this chapter, we will discuss the need for extending the power grid to increase the reliability of renewable energy supply and reduce the requirement for balancing power from conventional generators. In Section C, we summarise the analyses in which we have shown that building long-distance and intercontinental interconnections can be economically competitive. We consider the cheap and abundant renewable power in remote locations, as well as the opportunities presented by the time zone difference, for energy arbitrage between the continents. In that respect, we also introduce the vision of the Global Grid and a global electricity market environment. To facilicate our discussion on cross-border electricity trade, in Section D, we refer to the merchant transmission investment: an investment scheme for financing the building of new lines and how this depends on the market structure of the regions connected by such a line. In Section E, we outline the market operating schemes in different regions and then summarise the mechanisms for cross-border electricity trade. Finally, in Section F, we focus on the challenges that arise in an effort to couple different regional markets for cross-border electricity trade. Section $\mathrm{G}$ is the conclusion.

\section{B. The need for extending transmission infrastructure to balance demand} and supply from renewables

Power systems started to develop at a regional level in order to supply the load demand of larger areas from single generators. Interconnections among several countries emerged in the second half of the twentieth century. ${ }^{5}$ The main reason for interconnecting different power systems was to increase reliability and security of supply. If one area experienced a

\footnotetext{
${ }^{1}$ www.medgrid-psm.com

${ }^{2}$ www.offshoregrid.eu

${ }^{3}$ www.gobitec.org

${ }^{4}$ www.atlanticwindconnection.com

${ }^{5} \mathrm{http}$ ://theinstitute.ieee.org/technology-focus/technology-history/the-star-that-sparked-europes-power-grid513
} 
disturbance, neighbouring areas could provide the missing power for a given amount of time, until the fault is cleared. In the past two decades, however, interconnections have become the platform for an ever-increasing transfer of electricity and for electricity trade. With the increased integration of fluctuating energy sources, the role of interconnections is becoming more important.

Several studies investigating a very high RES-penetration in electric power systems have been carried out in Europe and the USA, and also in Asia. All these studies conclude that storage and increased interconnection capacity are major factors contributing to the balancing of RES variability and load.

Becker et al. (2014a) investigated the transmission needs in Europe for a fully renewable pan-European electricity supply. They considered high-resolution wind and solar data collected in Europe over eight consecutive years. They found that quadrupling today's net transfer capacity (NTC) of the European interconnections leads to a 33 per cent reduction in the need for balancing energy. Wind power benefits more from such interconnections than solar, as 'larger interconnected areas eliminate to a significant degree weather correlations that lead to generation patterns' (Becker et al. (2014a)).

Similar studies have been carried out for the USA. Becker et al. (2014b) investigated the optimal mix of wind and solar for a fully renewable US electricity system based on thirtytwo years of data for the whole contiguous USA. They determined the optimal mix for each of the ten Federal Energy Regulatory Commission (FERC) regions independently as well as for the whole of the USA. Among other results, they showed that interconnecting the ten FERC regions reduces the need for balancing power by up to 30 per cent compared with each region having to balance power supply and demand independently.

Mills and Wiser (2013) focused on the economic value of increased PV penetration in the US. They showed that absent any mitigation measure, more PV cannot help with the evening load (after the sun is down), which leads to a decrease in the marginal benefits of PV. One suggested remedy is to overdimension PV installations, namely installing PV capacity that exceeds the electricity demand during peak times. Despite this leading to a curtailment of PV production during peak hours, it will also lead to a flatter power production curve during the day.

A pan-Asian power grid has been suggested by Taggart et al. (2012), based on electricity market simulations. They found that the total cost of electricity could be reduced by up to US\$ 6.55 billion per year by interconnecting wind farms in China and solar PV installations in Australia. 
Aboumahboub et al. (2010) investigated the need for building additional 'peaking' gas power plants for balancing renewable energy. In their study they compared the number of necessary conventional power plants for balancing power in the case there are interconnecting lines between regions and in the case there are not. Their results for both the European and a potential Global Grid showed that by building a sufficient number of interconnecting lines, the need for dispatchable conventional power plants could be reduced by half to one eighth of the present level.

All these studies conclude that the benefit from interconnections is much more significant in the presence of a high proportion of wind in the renewable mix. On the other hand, if the renewable mix is mostly based on PV solar power, storage plays a significant role as this can provide the missing energy during the night.

In an electricity system supplied by renewable sources, storage is equally as important as a strong transmission grid and should be considered either as an alternative - when the majority of the renewable sources are small-scale plants such as rooftop solar PVs - or as a complement to long interconnections, especially when most of the renewable supply comes from remote wind farms and solar parks. Transmission grid studies already incorporate storage options in their projections for the future (e.g. Deutsche Energie-Agentur (dena), 2010). Bulk storage will be necessary for absorbing non-transmissible power and relieving congestion. Besides pump-hydro power plants, which are currently the most widespread type of bulk energy storage, new technologies, such as compressed-air, hydrogen, flywheel farms, or batteries ${ }^{6}$ can also be used in the future as bulk storage systems.

An additional factor, however, that needs to be taken into account when considering bulk storage is the necessity for grid reinforcements. An investigation of the integration of additional RES (Deutsche Energie-Agentur (dena), 2010) showed that even if there were storage able to absorb 100 per cent of the excess power, 65 per cent of the proposed grid reinforcements would still be necessary. In this respect, it should also be noted that comparing the bulk storage efficiency with transmission losses, a 6,000 km long high-voltage, direct current (HVDC) line has a greater efficiency presently than hydrogen or battery storage (ultra HVDC at $800 \mathrm{kV}$ exhibits 3 per cent losses per $1,000 \mathrm{~km}$ in comparison with the 50 per cent efficiency of hydrogen stoage).

\section{Long-distance interconnections: towards a global electricity environment}

\footnotetext{
${ }^{6}$ For example Tesla Motors is building a battery 'gigafactory', http://fortune.com/2014/10/28/tesla-closes-onfree-nevada-land-for-gigafactory/
} 
As we have seen in the previous sections, if we envision an electricity system supplied 100 per cent from renewables, it is necessary to build strong transmission grids that extend over large regions.

In our earlier work (Chatzivasileiadis et al. 2013, 2014) we propose the next natural step in introducing the vision of a globally interconnected power network: the Global Grid. The Global Grid aims at interconnecting the regional supergrids into one global electricity network. High-capacity long transmission lines will interconnect wind farms and solar power plants, supplying load centres with green power over long distances. Besides introducing the concept, in our earlier work (Chatzivasileiadis et al. 2013, 2014) we further highlighted the multiple opportunities it offers, and discussed possible investment mechanisms and operating schemes. Through cost-benefit analyses we showed that long-distance interconnections forming a Global Grid can be technologically feasible and economically competitive.

Recently, support for the concept of a global transmission grid powered by renewables has come from Zhenya Liu, the chief executive officer of the China State Grid Corporation. The China State Grid Corporation is one of the largest transmission system operators in the world, serving 128 million customers. ${ }^{7,8}$

Our analyses were based on real market price data, results from other studies and realistic assumptions. In this section we provide a summary of these results.

\section{Stages in creating a global power grid}

We identify three main drivers for the creation of a globally interconnected network. First, the need to harvest remote renewable energy resources, either further offshore or in deserts, will lead to continuously expanding regional supergrids. Second, taking advantage of the shift in peak demand periods between continents owing to time-zone differences, remote RES plants located at similar distances from two regions can connect and sell their power always at peak price. Third, the time zone difference between the continents creates opportunities for electricity arbitrage, which can lead to profitable electricity trade. Based on these drivers, the next paragraphs present the three main stages we envision as leading to the development of a Global Grid environment.

\footnotetext{
${ }^{7}$ Jenny Riesz, China leading the way to a global renewable grid (http://reneweconomy.com.au/2014/china-leading-way-global-renewable-grid-2-84674, accessed 19 September 2014).

${ }^{8}$ Zhenya Liu, Global Energy Interconnection, Elsevier, 2015
} 


\section{Harvesting RES from remote locations}

In this section we present two examples of harvesting the renewable energy potential from remote locations.

In an earlier publication (Chatzivasileiadis et al., 2013) we describe how tapping the renewable potential in Greenland can be a realistic example of progress towards global interconnections. Greenland was selected as a representative example for three reasons. First, it has a significant wind and hydro potential (Jacobson and Delucchi, 2011; Partl, 1977). Second, it is close to Iceland and Hammons et al. (1993) have already shown that the IcelandUK interconnection is a viable option. The two governments have already been discussing its possible realisation (Carrington, 2012). Third, all interconnecting sections along this route have lengths or sea depth comparable to currently existing projects (see Chatzivasileiadis et al., 2013 for more details). Therefore, we expect that Europe can benefit from importing wind and hydro power harvested in Greenland. Assuming that a wind farm in Greenland would be feasible, in the next sections we will present a more detailed analysis of how intercontinental trade could be a viable option in a transmission route over Greenland.

Similar to the case of Greenland is the case of a wind farm on Kerguelen islands (Chatzivasileiadis et al. (2014)). Kerguelen islands are located in the Indian Ocean, in approximately an equal distance between South Africa and Australia ( 4100 km), and they experience high and continuous winds. Based on the published wind data, onshore wind farms on Kerguelen Islands are expected to have a capacity factor of $60 \%-70 \%$. In our analysis we have accounted for three different wind capacity factors - 40\%, 50\%, 60\% - and two different submarine cable cost projections. Assuming that the wind farm revenues are generated by selling its power to South Africa and receiving the feed-in tariffs determined by the South African government (Wikipedia, 2013), in our study we determine what are the maximum wind farm production costs so that the wind farm, including the submarine cable investment, remains profitable. We find that for a capacity factor of $60 \%$, if its production cost is below 0.085 USD per kWh the wind farm on Kerguelen Islands can be competitive with wind farms located in South Africa. Such production costs can be currently achieved by large wind farms. Assuming a lower capacity factor of $40 \%$, then the wind production costs must not exceed $0.033-0.055 \mathrm{USD} / \mathrm{kWh}$. Taking into account that Delucchi and Jacobson (2011) project the production costs for onshore wind farms to start below $0.040 \mathrm{USD} / \mathrm{kWh}$, values such as $0.033 / \mathrm{kWh}$ can be highly probable by 2020 and beyond. 
In our earlier analysis (Chatzivasileiadis et al., 2013), we assumed that a $3 \mathrm{GW}$ wind farm off the eastern shores of Greenland is feasible and noted that some investors have decided to connect the wind farm with a $3 \mathrm{GW}$ line to Europe through Iceland and the Faroe Islands. We investigated whether a connection to North America would be profitable, taking into account two effects. First, owing to the time-zone difference, the wind farm will always be able to sell the power it produces at peak prices, e.g. 50 per cent of the time to Europe and 50 per cent of the time to the USA. Second, by creating a link between Europe and the USA, over Greenland, opportunities for electricity trade between the continents emerge. As the wind farm can produce power only for a limited time (we assume a capacity factor of 40 per cent), the cable capacity can be used for electricity trade for the remaining hours.

\section{Offering RES at peak prices}

In our earlier analysis (Chatzivasileiadis et al., 2013), we estimated that a $3 \mathrm{GW}$ cable can deliver about $20 \mathrm{TWh}$ per year - taking into account the transmission losses. From this, about $10 \mathrm{TWh}$ is allocated to the wind farm production. This means that for about 50 per cent of the time the cable capacity is available for electricity trade.

By building the transmission route Greenland-USA, we found that the costs per delivered $\mathrm{kWh}$ for the wind farm would increase by 21-25 per cent due to the additional investment costs. On the other hand, if off-peak prices are half of peak prices, the revenues will increase by 31-33 per cent if the wind farm always sells the power it produces at peak price; 50 per cent of the time to Europe and 50 per cent of the time to the USA. This results in additional profits of 7-12 per cent for the wind farm, as shown in Table 2.1.

Table 2.1: Wind farm in Greenland: Summary of the cost-benefit analysis of connecting the wind farm to the USA

\begin{tabular}{|l|l|l|l|}
\hline \multicolumn{2}{|l|}{ Transmission route: Europe-USA over Greenland; total cable energy capacity: 20 TWh per } \\
year & Wind farm production & \multicolumn{2}{|c|}{ Electricity trade } \\
\hline & $\sim 10 \mathrm{TWh}$ & $\sim 6 \mathrm{TWh}$ & $\sim 10 \mathrm{TWh}$ \\
\hline Utilisation & $(40 \%)^{\mathrm{a}}$ & $(30 \%)$ & $(50 \%)$ \\
$(\%$ of total time) & $7-12 \%$ & $24-27 \%$ & $39-42 \%$ \\
\hline Profit increase & & & \\
\hline
\end{tabular}


${ }^{\mathrm{a}}$ The wind farm is located in the middle of the Europe-USA path. As a result, it incurs only half of the transmission losses. That means that the same amount of power, e.g. $10 \mathrm{TWh}$, can be delivered over a shorter distance, resulting in a lower utilisation factor of the transmission path.

\section{Intercontinental electricity trade}

Besides selling the wind power produced, $10 \mathrm{TWh}$ of the cable capacity is available for electricity trade between the continents. Our analysis of the electricity trade opportunities is based on real price data for 2012. We obtained the hourly spot prices from the European Power Exchange ${ }^{9}$ in Germany and the PJM Interconnection ${ }^{10}$ in the USA. Owing to the timezone difference between the two continents, the two electricity markets experience their peak and lowest prices at different times. Our analysis is detailed in Chatzivasileiadis et al. (2014). We mainly examine two levels of utilisation: 30 per cent and 50 per cent. Our investigations show that through the revenues generated from the electricity trade, the route between Greenland and North America can be amortised within 10-12 years if the line is used 50 per cent of the time, and within 14-17 years if the cable is used for electricity trade only 30 per cent of the time. Translating these results into profits, we find that by conducting trade in electricity for 30 per cent of the time, the net profits $^{11}$ will increase by $24-27$ per cent compared with what the wind farm can achieve from selling its wind power only to the UK. If electricity trade is carried out for 50 per cent of the time, the profits may increase by up to 42 per cent. Table 2.1 summarises our results.

In conclusion, it seems that being connected to both continents would be a profitable strategy for the wind farm in Greenland. As detailed in this section, we investigated two possible sources of income that are created by building a transmission route from Europe to the USA over a wind farm in Greenland. The first is always selling the wind power produced at peak prices, either in Europe or in the USA and the second is by trading electricity between the continents. Although, we expect that the transmission route will be used for both options at the same time, we have shown that both options result independently in profitable operation of the wind farm.

\section{$I V$. Intercontinental interconnections by direct lines}

\footnotetext{
${ }^{9}$ European Power Exchange. www.epexspot.com

${ }^{10}$ PJM Interconnection LLC, www.pjm.com

${ }^{11}$ The investment costs of the additional cable have been deducted from the electricity trade revenues.
} 
In the section, we examine the direct connection of two continents by transmission lines. In an earlier analysis (Chatzivasileiadis et al. 2013) we considered the expected transmission costs per delivered $\mathrm{kWh}$ for a direct submarine cable between Europe and the USA. We estimated the cost of a $5,500 \mathrm{~km}, 3 \mathrm{GW}$ submarine cable to be in the range of 0.0166 euros to 0.0251 euros per kWh delivered. We ascertained that, except for the most expensive RES generators, it would apparently be more economical for the USA to import RES power from Europe than to operate its own fossil-fuel power plants. ${ }^{12}$

We then extended our analysis (Chatzivasileiadis et al., 2014) to find out whether the cost for a long submarine cable could be amortised through the revenues arising from the electricity trade between the two continents. Again, we used the hourly spot prices for 2012 provided by PJM in the USA and European Power Exchange (EPEX) in Germany. In our calculations we accounted for the transmission losses incurred by an 8,000 km long corridor connecting the USA with Germany. We estimate that for an 80 per cent utilisation of the cable (i.e. the cable is used only 80 per cent of the time), the amortisation period ranges from 18 to 28 years (Chatzivasileiadis et al., 2014). In the less favourable case where cable utilisation is 50 per cent, the amortisation period increases to about 23-35 years. Although such amortisation periods might not be very appealing for private investors, these results highlight that from a social welfare point of view, such a cable is beneficial to society.

\section{The Global Grid: an illustration}

Intercontinental interconnections, such as those discussed above, can lead to a globally interconnected network. Following our discussion on the economic feasibility of such interconnections, Figure 2.1 illustrates a possible Global Grid. We envision that the power supply of the Global Grid will depend on RES. Large renewable potential exists in remote locations, such as in deserts and offshore. Long HVDC lines will constitute the main corridors in a Global Grid environment, transmitting bulk quantities of power over long distances. HVDC lines are superior to AC technologies for long-distance transmission, as they exhibit lower losses, provide active and reactive power support, and can connect non-synchronous grids. More details on power generation and transmission through the Global Grid are published in Chatzivasileiadis et al. (2013).

\footnotetext{
${ }^{12}$ The result is based on electricity generation from conventional sources estimated by Delucchi and Jacobson (2011) with fuel cost projections based on US Energy Information Administration (2009). Unconventional sources of oil and gas such as oil sands and natural gas shales are also considered in the projections of the US Energy Information Administration (2009).
} 
Figure 2.1. Illustration of a possible Global Grid.

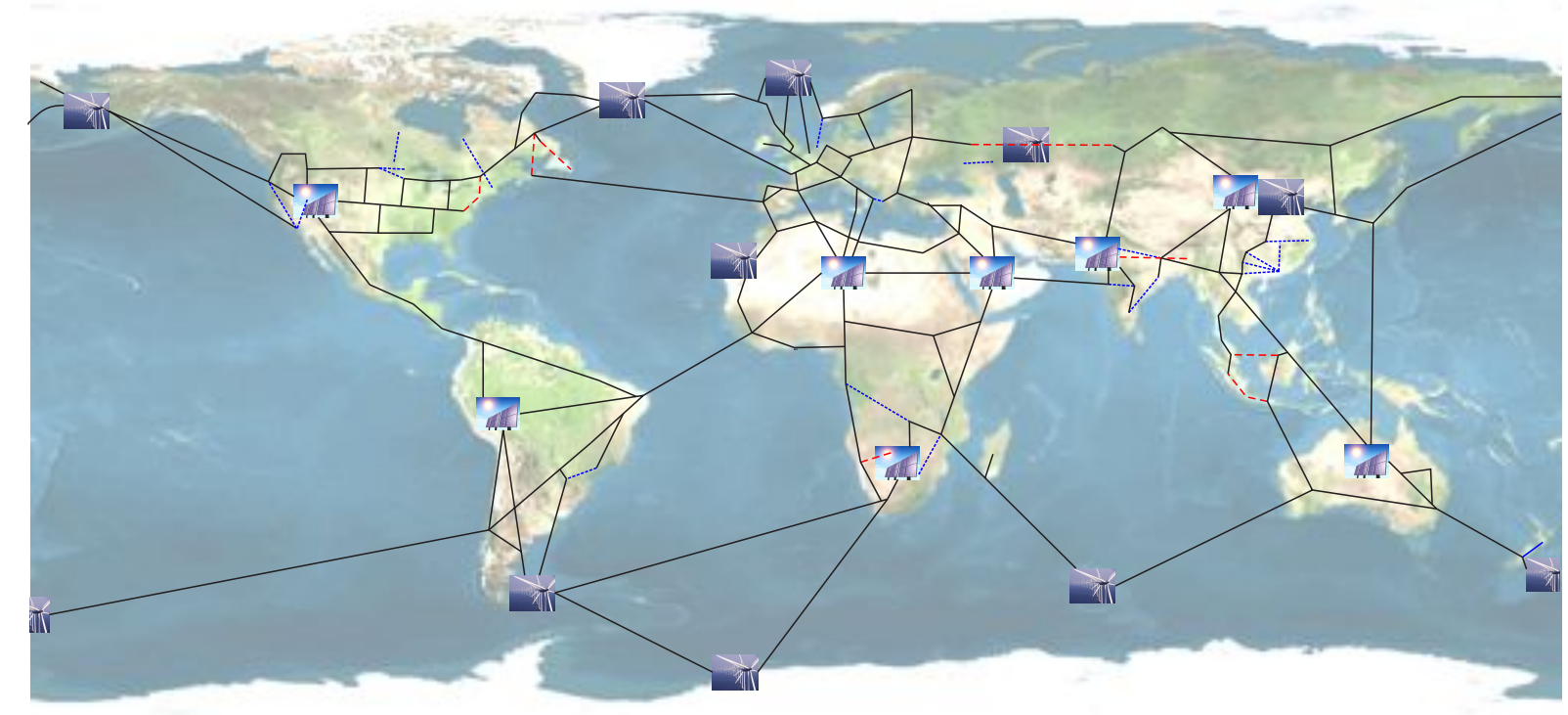

The location of the RES power plants is based on solar radiation maps, average wind speeds, and sea depths (Chatzivasileiadis et al., 2013)

\section{Merchant transmission investment}

In the previous sections we discussed the need for substantial reinforcements of transmission lines to decrease the need for balancing power, while also presenting results for the economic feasibility of new lines connecting different markets over long distances, e.g. Europe with the USA. Before moving on to the different market operation structures for electricity trade, we discuss the investment schemes for transmission infrastructure as their profits can depend on these market structures. Besides regulated investment, which is the most common type of transmission investment, here we focus on merchant transmission investment (MTI). MTI profits derive mainly from electricity trading and therefore the line's profitability is dependent on the market operation structure of the points the line connects.

Figure 2.2. Illustration of the revenue generation for the merchant transmission investment scheme 

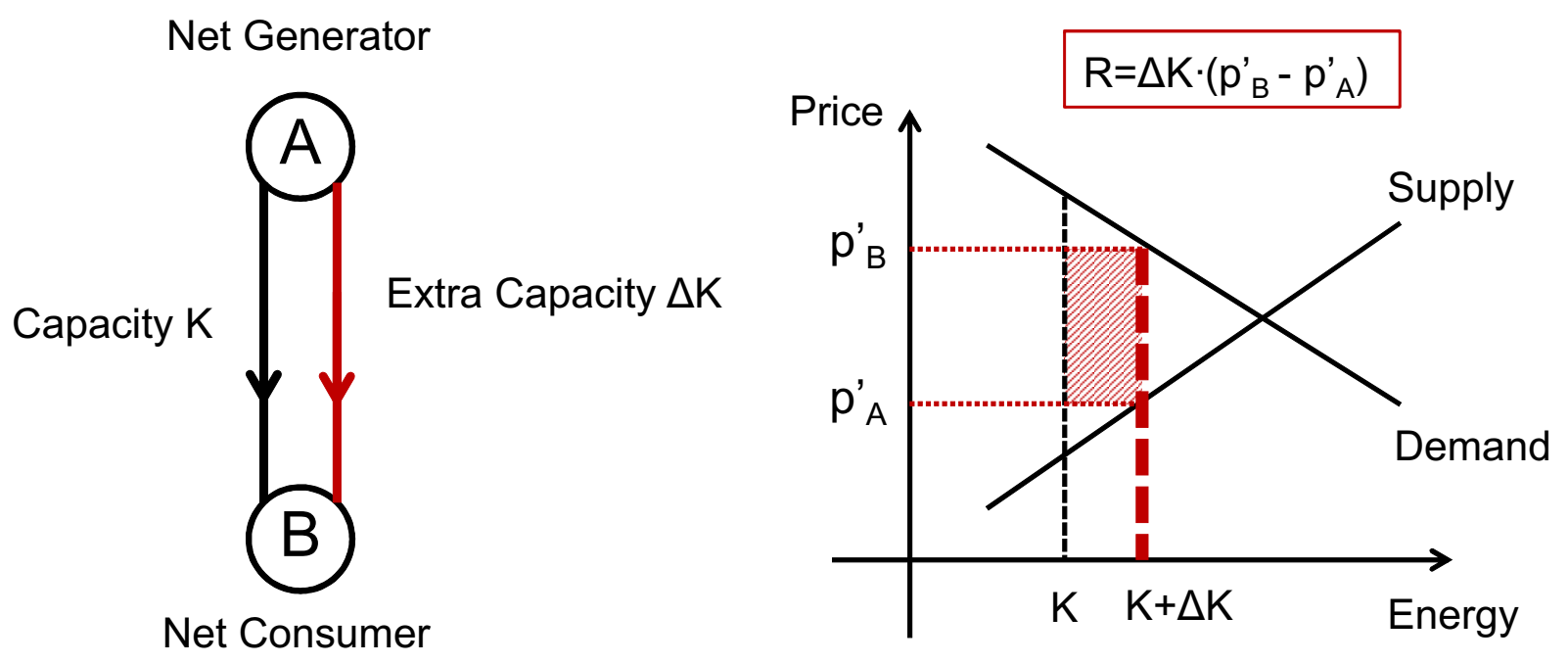

Figure 2.2. Illustration of the revenue generation for the merchant transmission investment scheme

The MTI, unlike regulated investments, does not need to be coordinated by a central authority, is not subject to regulation, and its profits derive mainly from trading electricity between the two areas that the transmission line connects. As a result, any interested party, including the transmission system operator (TSO) or transmission owners, can undertake a merchant investment as long as the difference in the electricity prices between the two areas allows for a profit margin. For more details, see Chatzivasileiadis (2012) and the references therein.

A comparison of transmission investment schemes (Chatzivasileiadis, 2012) concluded that different transmission investment models successfully tackle different inefficiencies but also have their own shortcomings. The literature concludes that developing good regulatory mechanisms that will also provide opportunities for merchant investors to develop projects seems to be a good approach, but at the same time poses a significant research challenge (Brunekreeft, 2004; Joskow and Tirole, 2005). As Brunekreeft suggests, controllable flows, namely HVDC lines and flexible AC transmission systems (FACTS), can operate sufficiently well under an MTI regime, overcoming several of its inefficiencies. For example BritNed and NorNed ${ }^{13}$ are DC interconnections that successfully follow the MTI model.

Concerning merchant transmission investments, owing to the benefits that interconnections offer, more such projects are expected to follow in the coming years,

\footnotetext{
${ }^{13} \mathrm{http}: / / w w w . t e n n e t . e u / n l / g r i d-p r o j e c t s /$ international-projects/norned.html; http://www.britned.com/
} 
connecting different regions and electricity markets. Owing to the size of the regional electricity markets, it could be envisioned that different owners will construct parallel lines, thus facilitating competition not only between the areas, but also between the lines. ${ }^{14}$ For example, assuming controllable flows, if a contracted energy transfer between points A and B can flow along two different paths, the corresponding line owners could compete over which path the energy follows.

\section{E. Cross-border electricity trade: state of play}

Cross-border electricity trading depends to a certain extent on the market structure of the individual regions that are connected with inter-tie lines. In this section we provide a summary of the most common electricity market operating schemes, which can be implemented on a regional basis. We then describe the cross-border capacity allocation mechanisms that lead to the coupling of the regional markets.

\section{Bilateral trading}

Bilateral trading takes place in most electricity markets, e.g. in the US and Europe. Under this scheme a seller and a buyer agree on the exchange of a certain amount of energy for a certain amount of time at a certain price. Bilateral contracts can be hourly, weekly, monthly or longer term, or they can be for peak or off-peak periods during a day. The advantage of bilateral trading is that it does not need a central market authority. Currently, in California, there are also proposals to abolish the day-ahead energy market, keeping only the 15-minute real-time unit commitment and the 5-minute real-time balancing market (economic dispatch), and allowing day-ahead transactions to be carried out through bilateral trading.

\section{Power exchange}

In a power exchange market structure, sellers and buyers participate in bidding over price and the quantity they can offer (or that they need, in the case of buyers). The market operator clears the market ensuring that the demand can be covered by the supply, dispatching the generators with the lowest bids. Although a power-pool market structure provides for the participation of electricity consumers, market regulations usually allow only large consumers to bid in the market. Small consumers usually pay a pre-agreed price and might be

\footnotetext{
${ }^{14}$ Peak electricity demand is in the range of several hundred GW for each region (e.g. Europe, North America or China), while the capacity of an interconnector is expected to be around a couple of GWs.
} 
represented by load-serving entities. Network constraints are not considered in a power exchange, but should be taken into account by the system operator. Where the market outcome violates network constraints, re-dispatching is necessary. Power pools are currently operating, for example, in Australia. ${ }^{15}$ Market clearing in Australia takes place every five minutes, and six dispatch prices are averaged every half hour to determine the spot price for each trading interval for each of the regions of the Australian National Electricity Market: Queensland, New South Wales, Tasmania, Victoria and South Australia.

\section{Locational marginal pricing}

In locational marginal pricing (or nodal pricing), the market operator receives bids (pairs of quantity and price) from power sellers and buyers and clears the market, taking into account network constraints. The price that a generator receives varies according to its location and is also dependent on transmission losses and transmission congestion. The advantage of locational marginal pricing over a power pool is that it takes into account network constraints. As a result the market outcome satisfies the need for reliable operation of the grid, while proper price signals are generated, taking into account congested transmission lines. On the other hand, the algorithm to solve such an optimisation problem is more complex than the economic dispatch taking place in the power exchange as it needs a full representation of the network. Furthermore, locational marginal pricing allows generators that are located downstream of congested lines to attain market power. Nodal pricing is currently implemented in all six organised markets in the USA, ${ }^{16}$ as well as in Singapore, among others. Poland is also in the process of implementing a nodal pricing market.

The market clearing varies in each market. In Singapore it is every 30 minutes. In California (CAISO) there is a day-ahead market as well as a real-time market which clears every 15 minutes for the unit commitment and every 5 minutes for real-time balancing (economic dispatch). In most US regions where an organised market exists, the market clearing mechanism co-optimises the dispatch of energy and reserves.

\section{Zonal pricing}

Zonal pricing - in accordance with nodal pricing - establishes different electricity prices for different locations in the network (Krause, 2007). In contrast to nodal pricing, where in the event of congestion prices might differ for every node, for zonal pricing a group of nodes is

\footnotetext{
${ }^{15} \mathrm{http}: / /$ en.wikipedia.org/wiki/National_Electricity_Market

${ }^{16}$ ISONE, NYISO, PJM, MISO, SPP, CAISO
} 
aggregated to one zone. These zones are mostly defined a priori as the concept focuses on certain flowgates, which may be subject to congestion. An example is the Norwegian system, where the system operator splits the national transmission system into two zones (north and south) in the event of congestion. If the demand for transmission services does not exceed system capabilities, different network zones are not established, and thus there is only one clearing price for the whole network. The European electricity grid also has a zonal pricing market structure.

\section{$V$. Ancillary services/reactive power markets}

Besides energy markets, there also exist ancillary services markets. Regulating energy, spinning and non-spinning reserves are traded in day-ahead and real-time markets in both the European and US electricity markets. Switzerland and Austria serve as an example of a coupled ancillary services market as each region is eligible to bid for ancillary services from the neighbouring region.

Switzerland also operates a reactive power market, allowing hydro generators in the distribution grid to offer reactive power and receive compensation for these services in order to keep the voltage level at certain buses in the transmission grid within secure limits (Zerva and Geidl, 2014).

\section{Cross-border transmission capacity allocation mechanisms}

Special transmission capacity allocation mechanisms have been developed to couple neighbouring markets and reserve transmission capacity in the inter-ties - also known as cross-border lines. In Sections VII and IX we distinguish between two main capacity allocation mechanisms.

\section{Explicit auctions}

In explicit transmission capacity auctions, bids are accepted to reserve transmission capacity on the inter-ties. To make use of this capacity, however, the bidder also needs to bid in an energy market, e.g. a power exchange. Thus, the electricity trade following this scheme requires two steps: first reserving the necessary transmission capacity in the interface to transmit power, and second, participating in an energy market to buy or sell the necessary amount of energy. 
The flow-based allocation mechanism is currently in use in central Europe (e.g. CWE: Central West European Region). This method couples the electricity trade with the physical flows resulting from it. A centralised auction office for the whole flow-based allocation (FBA) region is established, which maintains a simplified model of the power system under its responsibility. All interested parties submit bids to this office. FBA has several advantages, as it takes into account the loopflows induced from the trade (in the uncontrollable alternating current (AC) lines), allows for inter-regional trade, allocates energy contracts and transmission capacity at the same time, and supports the integration of regional power markets towards a single market. More information on how flow-based allocation avoids loopflows is provided in Chatzivasileiadis (2012) and the references therein.

In the European context, each zone is usually a single country or a TSO control area. For the cross-border flow-based allocation method no detailed modelling of the network inside each zone is necessary. However, TSOs derive power transfer distribution factors in order to represent the network on the interfaces, i.e. the inter-zonal interconnections. This information is then maintained by the central auction office.

$X$. Regions with no electricity markets, or with electricity markets under development Not all world regions have developed electricity markets. Arab states belonging to the Gulf Cooperation Council ${ }^{17}$ (GCC) plan to form a common wholesale market. The GCC Interconnection Authority will act as a gateway towards achieving a regional and pan-Arab power pool, becoming a broker between regional and international utilities and regulators (AlAsaad, 2009). Similarly, regions in the USA, such as the US Pacific Northwest region which is under the responsibility of Bonneville Power Authority - have no organised market.

\section{F. Challenges in cross-border electricity trade}

As we have seen in previous sections, transmission reinforcements will be necessary to smooth out the variability in the supply of renewables and in electricity demand. In our analysis, we also showed that interconnecting regions over longer distances can be technically feasible and an economically competitive options. At the same time, interconnecting different regions requires the coupling of the respective electricity markets to facilitate electricity trade and power exchange.

\footnotetext{
${ }^{17}$ GCC includes Saudi Arabia, Kuwait, Bahrain, Qatar, the United Arab Emirates, and the
} Sultanate of Oman. 
Several challenges arise from coupling regional electricity markets. We distinguish below between the political and regulatory challenges, and the challenges pertaining to the different market structures and investment schemes. The technical challenges are discussed in Chatzivasileiadis et al. (2013).

\section{Political and regulatory challenges}

By extending the markets over wider regions, load centres are expected to become increasingly dependent on imported energy. This raises at least two questions. The first concerns the security of supply. What is the impact of importing energy, for instance, from Russia or the African deserts? Desertec, which proposed to build concentrated solar power plants in the Sahara region and transport cheap renewable energy to Europe, showed that Europe could gain significant economic benefit from such an investment. However, following the unrest in the Arab countries, the concept has lost support. This problem is similar to those facing other energy carriers, such as oil or gas. The difference with electricity is, however, that it cannot be stored. ${ }^{18}$ This has both benefits and drawbacks. On the one hand, the importing country cannot be energy-independent unless it invests in its own generation capacity or in different interconnection paths in order to diversify the pool of its energy suppliers. On the other hand, from the viewpoint of the exporting country, renewable energy that cannot be stored will be lost, resulting in substantial economic loss. A regulating mechanism needs to be found that will share the risks of an energy 'embargo' between an exporting and an importing country.

A further challenge relates to the cost of imported electricity. Assuming that different countries follow different policies with respect to environmental taxes, e.g. the carbon tax, the cost of energy will differ. To illustrate this challenge let us assume that cross-border electricity trade takes place between Russia and the EU countries. We further assume that the EU has imposed taxes on all conventional generation, so that production from renewable technologies in Europe is cheaper than gas, nuclear, and coal generation. On the other hand, we assume that Russia has low-cost gas-fired power plants, and does not impose any environmental taxes on $\mathrm{CO}_{2}$ or other emissions. In such a case importing electricity from Russia may be cheaper than producing electricity from renewables in power plants in Europe. Several questions arise. Will this imported energy count towards meeting the environmental targets the EU has set? Should there be an import tax, similar to the tolls that are imposed for

\footnotetext{
${ }^{18}$ At least for the moment, there is no technology that can store large amounts of electricity in an efficient way.
} 
the import of goods? Lower cost energy would be beneficial for the European economy, but what is the economic impact of the environmental damage in Russia or globally?

An additional challenge relates to the development of microgrids. Drivers such as a more resilient grid and the decrease of distribution losses lead to the installation of more microgrids. Local generation can act both as an alternative and as a complement to large centralised generation and bulk power transmission. Regulation plays a significant role in this case too. How will the cost of rooftop PV systems and batteries and the pricing scheme for distribution tariffs evolve? If local generation becomes abundant, the energy flowing on the distribution network will significantly decrease resulting in a significant drop in revenue for the distribution companies. Depending on how the transmission and distribution tariffs are regulated, microgrids might opt to disconnect and operate off-grid in an effort to avoid the grid tariffs. ${ }^{19}$ How will this affect the transmission network and cross-border electricity trade? And what will be the impact on the available budget - and need - for transmission investments? On the other hand, as long as the microgrids remain connected, proper regulating mechanisms for electricity trade where microgrids can also participate as entities will be necessary.

The widespread development of microgrids will also depend on the cost for installing new distributed generation power plants. Although the cost of distributed generation has significantly fallen in recent years, Dinica (2011) suggests that in the long run a flattening out or a U-shaped curve for production costs would be more likely. For wind generation, she notes that '[in Spain] the increases in technological performances and installed capacity per turbine did not compensate for the decrease in resource quality and availability', and this resulted in an increase of the wind power production costs from 5.1-6.5 euro cents per kWh in 2005 to an estimated 5.6-7.0 euro cents per $\mathrm{kWh}$ in 2010. On the other hand, this trend is not currently observed for solar PV panels owing to economies of scale and significant technological advances. As long as the trend that Dinica suggests holds for both wind and solar PV in the future, we expect that local generation will act as a complement rather than as a complete alternative to bulk renewable generation. Both will be necessary so that small

\footnotetext{
${ }^{19}$ At the moment the cost of battery storage is significant for large energy capacities. Given that solar irradiation in central Europe is about three times higher during the six sunniest months (April-September) than in the six least sunny ones (October-March), the necessary battery capacity for seasonal storage and the associated cost is very high. This will, therefore, be the main reason at present for deciding against disconnecting the microgrids; however technological (or regulatory) developments might change this in the future.
} 
residential and large industrial and commercial loads can be equally supplied with 'green' energy.

Last but not least, the need for coordination of activities between the regional regulators and a common coordinating body will be necessary. For example, in North America, the North American Electric Reliability Council (NERC) is a regulatory authority whose mission is to ensure the reliability of the bulk power system in Canada, the USA and part of Baja California in Mexico. ${ }^{20}$ Similarly, efforts towards an Internal European market have led to the Agency for the Cooperation of Energy Regulators (ACER) recently being formed in Europe. ${ }^{21}$ As long as regions extend beyond the central European or the North American boundaries, e.g. with interconnections to Asia or Latin America respectively, these bodies should also be extended.

\section{Challenges in market operation}

Considering cross-border flows and market structures, the first question is whether we need a more centralised or decentralised market operation scheme. Europe seems to be moving to a more centralised structure with flow-based allocation mechanisms. California, by contrast, has recently discussed maintaining only bilateral trading for day-ahead trading in the future.

Taking into account that an HVDC overlay grid connecting different market regions may exist in the future, if we opt for more centralised coordination of the electricity trade various options are available. One possible option is a hierarchical market model, equivalent to the schemes currently proposed for a flow-based allocation mechanism. In this case we distinguish the DC grid from the underlying regional AC networks. An interregional market can be formed in which each regional market participates as an individual player. ${ }^{22}$ Here, considerations should be made in a fair and transparent way so that the HVDC flows can be calculated. The advantage of such a scheme is that the structure of each regional market probably does not need to be significantly modified.

Another alternative is a more 'horizontal' operation of the interregional market. For this option, two possibilities should be distinguished. First, an operation similar to the current power exchanges could be envisioned. The second possibility is more complex, where the interregional market operator, taking into account the whole grid and local grid constraints,

\footnotetext{
${ }^{20}$ Www.nerc.com

${ }^{21}$ www.acer.europa.eu

${ }^{22}$ Individual players need not have the size of regional markets. They can also comprise a certain group of entities (above a certain MW level of production or consumption) that belong to the same energy market.
} 
clears the market and determines the power flows. Here, as in the case of the hierarchical model, a proper mechanism for calculating the flows must be designed. Such a scheme, however, introduces significant complexity and raises questions, such as whether to opt for a nodal pricing scheme or a zonal scheme where several nodes are aggregated to a node.

For information on technical implementation of an optimal power flow in multi-area AC and HVDC grids under different operation schemes, the interested reader can refer to Iggland et al. (2014). A solution determined through an optimal power flow maximises social welfare, determines the dispatch of the generators, and the flow on the HVDC lines. The pricing of the multi-terminal HVDC nodes, however, remains an open question. The locational marginal pricing concept does not apply as well to HVDC grids, given that the HVDC flows are controllable.

Challenges arise also from the introduction of new investment schemes. As already mentioned, the MTI model applies well to HVDC lines. Given the numerous advantages of such lines for long-distance transmission, we expect that in the future several HVDC lines will form an HVDC grid, and some of these HVDC lines could be under the MTI model. In such an environment several operational and regulatory questions arise. One could envision competition between parallel HVDC lines. Do merchant transmission investments need to be regulated, and if so, how? Additionally, assuming that an HVDC line connects a nodal pricing market with a zonal market, how can the revenues of the line be calculated? And what happens if an HVDC extends over a whole country? For example, if country A is adjacent to country B, and country B is adjacent to country C, what happens if we build a line that directly connects country A with country C passing through country B? With the HVDC technology, in order for country B to have access to the transmitted power, a multi-terminal converter is necessary. If no such converter is available and no trade with country B takes place, is country B somehow eligible for part of the profits generated by the HVDC line just because it offers rights of way?

\section{G. Discussion and conclusions}

Aiming at a fully renewable system, as we shift from fully dispatchable conventional generators to fluctuating RES, it is necessary to rethink how to design, plan and operate the grid. Efficient storage and transmission reinforcements are two of the most important factors required to balance renewable supply and demand and maintain a reliable electricity supply avoiding carbon emissions. Reinforcing transmission interconnections and extending the grid over larger regions reduces the necessary balancing power, especially for wind generators, 
that should otherwise be provided from conventional generators. At the same time, grid expansion allows the harvesting of renewable potential abundant in remote locations, such as off-shore or in deserts. As larger regions become interconnected, mechanisms for transparent and efficient cross-border energy trading should be put in place to facilitate the power exchange between regions.

In this chapter, we first summarise our previous work on the feasibility of longdistance interconnections from an economic perspective. We envision that such interconnections can form the basis of a Global Grid (Chatzivasileiadis et al., 2013, 2014). We show that connecting Europe with the USA over a wind farm in Greenland can be profitable in two ways: first, by always selling the wind power at peak prices, half of the time to Europe and half of the time to the USA, and, second, through electricity trade between the regions. We find that the wind farm profits could increase by 7-12 per cent in the first case and by up to 42 per cent in the second case. We further investigate direct interconnections between Europe and the USA through submarine cables. Our analysis is based on real price data from Germany and PJM in the USA. We find that the amortisation period for such a cable would lie between eighteen and thirty-five years, assuming 50-80 per cent utilisation of the cable.

Next, we focus on the challenges emerging from cross-border electricity trade when interconnecting larger regions. To facilitate this, first we provide a short discussion on investment schemes for new transmission lines, focusing on the Merchant Transmission Investment model. This is a scheme that can apply well to the installation of new HVDC lines, and which is dependent on the market structure of the regions the line connects. Subsequently, we focus on the main market operating schemes for electricity trade in different regions as well as the market coupling schemes and the transmission capacity allocation mechanisms for cross-border lines. We summarise the explicit capacity allocation and flowbased allocation scheme.

We then elaborate on the numerous challenges that emerge from long-distance interconnections and the coupling of several regional markets. We distinguish between political and market operation challenges. We discuss regulatory matters, such as the cost of imported electricity if the exporting and importing regions follow different policies with respect to environmental taxes. We further mention challenges pertaining to the market operation in the presence of an HVDC overlay grid and the coupling of nodal and zonal markets, as well as the regulatory and operational framework of an MTI coupling different markets. 
In conclusion, we note that coupling several regional markets with the long-term vision of creating a global electricity market environment presents several challenges. Identifying these challenges and working on solutions is the first step towards the creation of larger electricity markets leading to increased competition, lower electricity prices and potentially greater security of supply.

\section{Bibliography}

Aboumahboub, T., Schaber, K., Tzscheutschler, P. and Hamacher, T. 2010. 'Optimization of the utilization of renewable energy sources in the electricity sector', in Proceedings of the 5th IASME/WSEAS International Conference on Energy \& Environment (EE '10).

Al-Asaad, H. K. 2009. 'Electricity power sector reform in the GCC region', The Electricity Journal 22(9): 58-64.

Becker S., Rodriguez R.A., Andresen G.B., Schramm S. and Greiner M. 2014a.

'Transmission grid extensions during the build-up of a fully renewable pan-European electricity supply', Energy 64: 404-18.

Becker S., Frew B.A., Andresen G.B., Zeyer T., Schramm S., Greiner M. and Jacobson M. Z. 2014b. 'Features of a fully renewable US electricity system: Optimized mixes of wind and solar PV and transmission grid extensions', Energy 72: 443-58.

Boute, A. and Willems, P. 2012. 'RUSTEC: Greening Europe's energy supply by developing Russia's renewable energy potential', Energy Policy 51: 618-29.

Brunekreeft, G. 2004. 'Market-based investment in electricity transmission networks: controllable flow', Utilities Policy 12(4): 269-81.

Carrington, D. 2012. 'Iceland's volcanoes may power UK', The Guardian 11 April, http://www.guardian.co.uk/environment/2012/apr/11/iceland-volcano-green-power, accessed: 16 September 2014.

Chatzivasileiadis, S. 2012. 'Transmission investments in deregulated electricity markets', Technical Report, ETH Zurich.

Chatzivasileiadis, S., Ernst, D. and Andersson, G. 2013. 'The Global Grid', Renewable Energy 57: 372-83.

Chatzivasileiadis, S., Ernst, D. and Andersson, G. 2014. 'Global power grids for harnessing world renewable energy', in Jones, L.E. (ed.) Renewable Energy Integration: Practical Management of Variability, Uncertainty and Flexibility in Power Grids. London: Elsevier Academic Press, pp. 175-88. 
Czisch, G. 2011. Scenarios for a future electricity supply: cost-optimized variations on supplying Europe and its neighbours with electricity from renewable energies. Stevenage: Institution of Engineering and Technology (IET).

Delucchi, M.A. and Jacobson, M.Z. 2011. 'Providing all global energy with wind, water, and solar power, Part II: Reliability, system and transmission costs, and policies', Energy Policy 39(3): 1170-90.

Deutsche Energie-Agentur (dena). 2010. dena Grid Study II - Integration of renewable energy sources in the German power supply system from 2015-2020 with an outlook to 2025. Berlin: German Energy Agency.

Dinica, V. 2011. Renewable electricity production costs - a framework to assist policymakers' decisions on price support. Energy Policy 39: 4153-67.

European Commission. 2008. Impact assessment on the EU's objectives on climate change and renewable energy. Brussels: European Commission.

Hammons, T., Olsen, A., Kacejko, P. and Leung, C. 1993. Proposed Iceland/United Kingdom power link - An in-depth analysis of issues and returns. IEEE Transactions on Energy Conversion 8(3): 566-75.

Hand, M.M., Baldwin, S., DeMeo, E., Reilly, J.M., Mai, T., Arent, D., Porro, G., Meshek, M., Sandor, D. (eds.) 2012. National renewable energy laboratory, renewable energy futures study. 4 vols. (NREL/TP-6A20-52409). Golden, CO: National Renewable Energy Laboratory, http://www.nrel.gov/analysis/re_futures/, accessed 20 June 2012.

Iggland, E., Wiget, R., Chatzivasileiadis, S. and Andersson G. 2014. Multi-area DC-OPF for HVAC and HVDC grids, submitted to IEEE Transactions on Power Systems.

Jacobson, M.Z. and Delucchi, M.A. 2011. Providing all global energy with wind, water, and solar power. Part I: Technologies, energy resources, quantities and areas of infrastructure, and materials. Energy Policy 39(3): 1154 -69.

Joskow, P. and Tirole, J. 2005. Merchant transmission investment. The Journal of Industrial Economics, 53(2): 233-64.

Krause, T. 2007. Evaluating congestion management schemes in liberalized electricity markets applying agent-based computational economics. $\mathrm{PhD}$ thesis, ETH Zurich, Switzerland.

Mills, A. D. and Wiser, R. H. 2013. 'Changes in the economic value of photovoltaic generation at high penetration levels: a pilot case study of California,' IEEE Journal of Photovoltaics 3(4): 1394-1402. 
Partl, R. 1977. 'Power from glaciers: the hydropower potential of Greenland's glacial waters', IIASA Research Report RR-77-020.

State of California. 2011. Senate Bill X1-2 (sbx1 2).

Taggart, S., James, G., Zhaoyan, D., Russell, C. 2012. 'The future of renewables linked by a transnational Asian Grid', Proceedings of the IEEE 100:2 348-59.

Wikipedia. 2013. 'Energy in South Africa', http://en.wikipedia.org/wiki/Energy_in_South_ Africa, accessed 17 December 2013.

Zerva, M. and Geidl, M. 2014. 'Contribution of active distribution grids to the coordinated voltage control of the Swiss transmission system', 18th Power Systems Computation Conference (PSCC), Wroclaw, Poland, 18-22 August. 